\title{
Object-based allocation of visual attention in response to exogenous, but not endogenous, spatial precues
}

\author{
ANDREW D. MACQUISTAN \\ University of Alberta, Edmonton, Alberta, Canada
}

\begin{abstract}
Two rectangular objects were presented in the visual field, and subjects' attention was directed to a location on one rectangle by either an endogenous or an exogenous spatial precue. Similar experiments by Egly, Driver, and Rafal (1994) have shown an object-based effect: slower target identification when the target was presented on the uncued object, even when the spatial proximity of the target's and the cue's location was controlled. The experiment reported here showed that this object-based effect occurs only for exogenous cues. Considered in the light of other literature on spatial cuing, it seems that attention is influenced by nearby objects when exogenously directed to a location, but it is independent of such objects when endogenously directed to a location.
\end{abstract}

Visual selective attention can be thought of as the ability to select response-relevant information from among competing sources in the visual field (Kahneman \& Treisman, 1984). Models of attentional selection can be divided into two general types: space-based models, which emphasize how spatial properties such as the location or proximity of stimuli affect selection, and objectbased models, which emphasize how objects and groups affect selection (Duncan, 1984; Kanwisher \& Driver, 1992; Tipper, 1992). Object-based models are supported by findings such as the stronger response competition from stimuli belonging to the same object or group as a target (Baylis \& Driver, 1992; Kramer \& Jacobson, 1991), the greater frequency of feature migrations within rather than between objects and groups (Prinzmetal, 1981), the difficulty of simultaneously identifying two properties of two different objects (Duncan, 1984), and other similar results (Kanwisher \& Driver, 1992; Tipper, 1992). Support for space-based models includes the results of spatial cuing experiments (Posner, Snyder, \& Davidson, 1980) in which a subject, while maintaining fixation on a central location, is cued to attend to an eccentric location in the visual field. Attention is measured by presenting a target for the subject to detect or identify. Typically, the subject's responses are faster and/or more accurate for targets presented at a cued rather than an uncued location,

The research reported here formed part of the author's dissertation at the University of Alberta. Data collection was supported through an NSERC operating grant to Peter Dixon, and the assistance of Dean Taylor in running subjects was greatly appreciated. The author would like to thank Peter Dixon, Alan Kingstone, and Norman Brown for their advice on conducting this research, and especially Ray Klein and an anonymous reviewer, whose criticisms of an early version of the paper led to the experiment reported here. Correspondence should be addressed to A. D. Macquistan, Department of Psychology, University of Alberta, Edmonton, AB, Canada T6G 2E9 (e-mail: macquis@ psych.ualberta.ca). and the subject's response times and/or errors increase with increasing separations of the cued location and the target's location (Eriksen \& Hoffman, 1974; Posner, 1980; Posner et al., 1980). These findings are consistent with the importance of location and spatial proximity in space-based models of attention.

Research in the spatial cuing paradigm has also demonstrated that the type of cue used to direct attention is important (see Klein, Kingstone, \& Pontefract, 1992, for a review). Endogenous cues, such as an arrow or number at fixation, are most effective if the stimulus onset asynchrony (SOA) between cue and target is $300 \mathrm{msec}$ or longer, and if the cue is predictive of the target's subsequent location. Exogenous cues, sudden perceptual events at a location such as a flash of light or the onset of a bar marker, are most effective at SOAs of 100-150 msec (Müller \& Rabbitt, 1989; Nakayama \& Mackben, 1989) and draw attention even if they are not predictive of the target's location. The effect on response times of exogenous cuing are larger when a target's identification requires the integration of features than when it does not, while the effects of combining endogenous cuing with the same manipulations have additive effects in response time (Briand \& Klein, 1987). In contrast, manipulations of stimulus likelihood show additivity when exogenous cues are used, but interact with cuing when endogenous cues are used (Klein, 1994; Klein \& Hansen, 1990). Exogenous cuing is also associated with inhibition of return (Maylor, 1985), a phenomenon not seen with endogenous cues. These differences have led some researchers to argue that different processes are engaged by exogenous and endogenous cues (Briand \& Klein, 1987; Klein, 1994; Klein \& Hansen, 1990; Müller \& Rabbitt, 1989; Nakayama \& Mackben, 1989).

Recently, object-based effects in the location cuing paradigm have been reported by Egly and his associates (Egly, Driver, \& Rafal, 1994; Egly, Rafal, Driver, \& Starrveveld, 

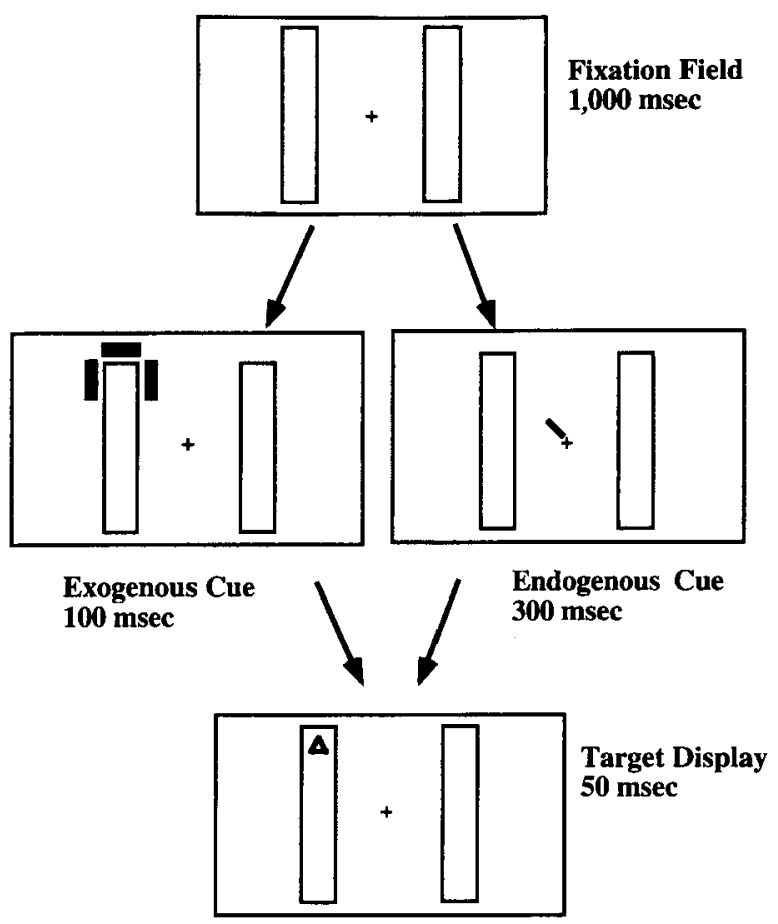

Figure 1. Example of stimuli and time course of trials for the cued object/cued location condition, for both exogenous and endogenous cues.

1994). They manipulated objects by presenting two outline rectangles in the visual field, equidistant from fixation, with the separation between the rectangles equal to their length. A sudden, 100-msec brightening of one end of one rectangle was used to direct the subject's attention, and a detection target appeared $300 \mathrm{msec}$ after the cue's onset. The target was most often presented at the cued location, but was also presented at the uncued end of the cued rectangle, and at the equally distant end of the uncued rectangle. If selection was only determined by spatial factors, then the equal spatial separation between the cued location and the two uncued locations should have resulted in equal response times (Henderson \& Macquistan, 1993). Consistent with space-based theories, detection of targets presented on the uncued location on the cued object was slower than detection of targets at the cued location. In addition, consistent with object-based models of attention, detection of targets presented at the uncued location on the cued object was faster than detection of targets presented at the equally distant end of the uncued rectangle.

In light of the differences between the effects of exogenous and endogenous cues, it is worth noting that Egly's cues have both endogenous properties, in that the cue was predictive of the target's subsequent location and the cue-target SOA was $300 \mathrm{msec}$, and exogenous properties, in that the cue was a physical change in the visual field at the cued location. ${ }^{1}$ In order to examine whether this object-based effect is sensitive to the kind of cue used to direct attention, purely exogenous and un- ambiguously endogenous cues were compared in the experiment reported below.

\section{METHOD}

\section{Subjects}

Two groups of 47 subjects each ( 94 total) participated in the experiment in return for course credit. All had normal or corrected-to-normal vision (according to self-report), and none had previously participated in a spatial cuing experiment. Ten subjects in each group had accuracies of less than $80 \%$ in one or more conditions and were therefore excluded from the subsequent analysis, leaving 37 subjects per group (74 in total).

\section{Apparatus}

Experiments were run on a Macintosh computer. Responses were made on the " $z$ " and "/" keys of the keyboard. Response times were measured by an on-board clock.

\section{Stimuli}

Examples of the stimuli and time course of the two types of trials are shown in Figure 1. The stimuli were presented on a white background. The fixation point subtended $6^{\prime} \times 6^{\prime}$, and the rectangular objects subtended $10^{\circ} \times 2^{\circ}$, with their midpoints $3^{\circ} 53^{\prime}$ on either side of the fixation point. The rectangles were always parallel to each other, were oriented either vertically or horizontally, and were shaded gray to make them clearly discriminable as coherent objects that were distinct from their background. The triangular targets subtended $1^{\circ}$ along the base and $50^{\prime}$ in height. They were always presented at the ends of the rectangles, $5^{\circ} 48^{\prime}$ from fixation. Targets and fixation point were drawn in black.

Two types of cue were used. The exogenous cue consisted of three lines forming a segmented $\mathrm{C}$ shape around the end of a rectangle. Each line was $36^{\prime}$ wide and $2^{\circ} 9^{\prime}$ long, and was separated from the sides of the object by $36^{\prime}$. The endogenous cue was a line segment oriented at $45^{\circ}, 135^{\circ}, 225^{\circ}$, or $315^{\circ}$ from vertical to indicate a target location. It was presented with one end $30^{\prime}$ from fixation and subtended $1^{\circ} 9^{\prime}$ in length and $22^{\prime}$ in width.

\section{Procedure}

Subjects were run individually, each participating in one block of at least 20 practice trials and two blocks of 192 trials. Data from the practice trials were not analyzed. Type of cue was manipulated between subjects: Subjects participated in either the exogenous cue group or the endogenous cue group. Procedures for the two cue groups were identical except as noted below.

Upon arriving at the experiment, subjects received a verbal description of their task, and any questions that they had were answered. The importance of maintaining fixation throughout each trial was stressed. They then participated in a block of practice trials. During the practice trials, the experimenter was seated where he could observe the subjects' eyes, and the practice block continued until subjects had completed 20 practice trials without eye movements. Two blocks of test trials followed without the experimenter present

Exogenous cue trials. Each trial began with a blank screen. When the computer was ready to begin the trial, the fixation cross appeared at the center of the screen. Subjects initiated the trial by pressing the space bar. The rectangles then appeared, oriented horizontally or vertically with equal probability. They remained on the screen throughout the trial.

After the rectangles had been on screen for $1 \mathrm{sec}$, the exogenous cue was presented for $100 \mathrm{msec}$. The cue was equally likely to occur at either end of either rectangle. Immediately after the cue's offset, the triangular target was presented for $50 \mathrm{msec}$ at one of the four possible target locations. The target could be pointing up or down with equal likelihood and could occur with equal probability at either end of either rectangle, regardless of the cue's location. This formed a four-level factor of cue-target relationship: cued object/cued location (target at the cued end of the cued object); cued object/near location (target at the uncued end of the cued object); uncued object/near location (the end of the uncued object nearest the cued location); and uncued object 


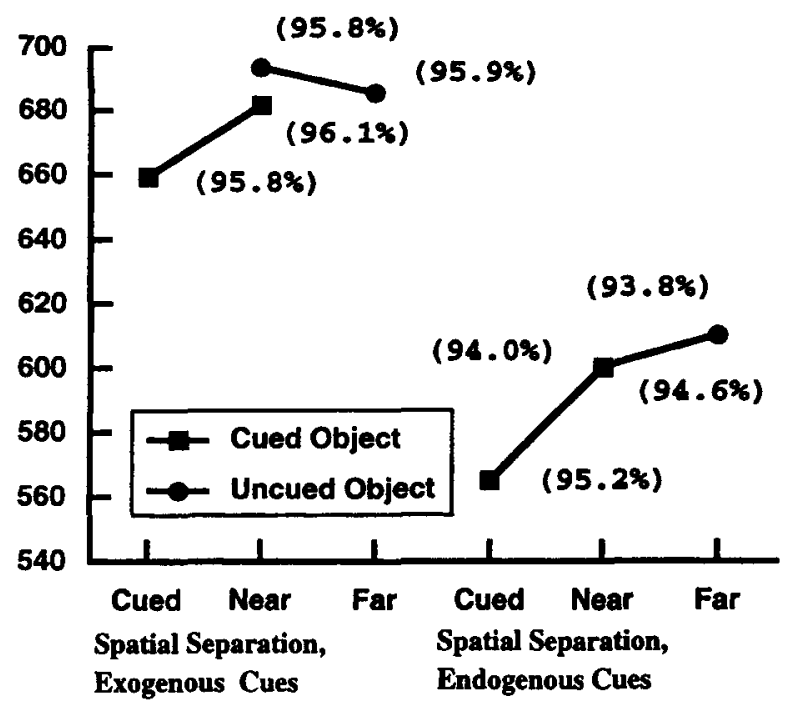

Figure 2. Mean response times for exogenous and endogenous cue groups, with mean accuracies in parentheses. In the endogenous cue group, the mean response times for the cued object/near location and the uncued object/near location conditions were both 600 msec.

far location (at the end of the uncued object diagonally opposite the cued location). The subjects' task was to indicate by keypress, as quickly and accurately as possible, the orientation of the target (up or down).

Endogenous cue trials. Endogenous cue trials differed from exogenous cue trials in three ways: First, the endogenous cue, a line segment at fixation indicating a location, was used. Second, the cue was present on screen for $300 \mathrm{msec}$ instead of $100 \mathrm{msec}$, for a cue-target SOA of $300 \mathrm{msec}$. Finally, the cue was predictive of the target's subsequent location. To facilitate comparison with Egly, Driver, and Rafal's work (1994; Egly, Rafal, et al., 1994), the endogenous cue indicated the target's subsequent location on $75 \%$ of trials: 144 trials in each block were cued object/cued location trials, 16 were cued object/ near location trials, 16 were uncued object/near location trials, and 16 were uncued object/far location trials.

\section{RESULTS}

\section{Response Times}

After excluding the subjects with less than $80 \%$ accuracy, the analysis of the remaining 74 subjects' response time data was based only on correct responses, with response times faster than $100 \mathrm{msec}$, slower than $3,000 \mathrm{msec}$, or more than $3 S D$ s from the mean of that subject for that condition excluded from analysis. Mean response times and accuracies in the cuing conditions for both groups are presented in Figure 2.

Subjects excluded for high error rates tended to produce a large number of keying errors (pressing keys other than the "z" or "/"). Most likely, these subjects used a poor strategy for producing responses, such as pressing the space bar with one finger and then using the same finger to press a response key. This raises the possibility that the remaining subjects may not have been drawn from a single population with homogenous variance, but from two or more populations that differ in how they performed the task. For this reason, nonparametric tests of significance were used to avoid making assumptions of normality and homoscedasticity.

The endogenous and exogenous cue groups were analyzed separately using Friedman's $F$, with $k=4$ levels of cue-target relationship and $n=37$ subjects for each analysis. For both groups, the effect of cue-target relationship was significant. For the exogenous cue group, $\chi_{r}^{2}=34.39$ $(p<.01)$, and the sums of the ranks were 57 (cued object/cued location), 88 (cued object/near location), 117 (uncued object/near location), and 108 (uncued object/far location). For endogenous cues, $\chi_{r}^{2}=45.16(p<.01)$, and the corresponding sums of the ranks were 48, 107, 99, and 116.

In either cue group, an object-based effect would have been evident if the cued object/near location response times had been significantly faster than those for the uncued object/near location. If only one cue type had produced an object-based effect, an interaction would be predicted, with one cue type group showing the difference between cued object/near location and uncued object/near location, and the other showing no such effect. Dunn's procedure, controlled at $p=.05$ per group, ${ }^{2}$ was used to make pairwise comparisons of summed ranks within each group. In the exogenous cue group, the difference of summed ranks between the cued object/near and the uncued object/near conditions was 29 , a significant difference reflecting the $12-\mathrm{msec}$ difference in mean response times. In the endogenous cue group, this comparison was not significant. The difference in summed ranks was -8 , reflecting a $0-\mathrm{msec}$ difference. The predicted interaction was tested with a Wilcoxon signed rank test, and proved reliable $\left(\mathrm{W}_{x}=1,174, z=-2.308, p<.05\right)$.

\section{Accuracy}

Calculation of mean accuracies included those trials that had been classified as outliers in the response time analysis. Again, both cue groups were analyzed separately, using Friedman's $F$. Accuracy did not differ significantly over cue-target relationship in the exogenous cue group $\left(\chi_{r}^{2}=<1\right)$ or in the endogenous cue group $\left(\chi_{r}^{2}=6.49, p>.05\right)$. The sums of the ranks for the exogenous cue group were $93.5,97,90.5$, and 89 , while the sums for the endogenous group were 103.5, 100.5, 84.5, and 81.5. Lower sums reflect lower accuracies, and the fractional values result from tied scores. In the endogenous cue group, the difference in ranks between the cue object/ near location and the uncued object/near location conditions was in the right direction for an object-based effect in accuracies, but neither the overall test nor the pairwise comparisons were significant. Also, the corresponding difference in response time ranks was in the opposite direction, which suggests that the pattern in accuracy may be a speed-accuracy tradeoff.

\section{DISCUSSION}

Object-based effects in the location cuing paradigm depend on the type of cue used to direct attention: Only following an exogenous cue is the cued object/near location faster than the uncued object/near location. This implies that object-based effects in the spatial cuing par- 
adigm depend on those properties that the exogenous cues share with Egly, Driver, and Rafal's (1994) cues, such as being presented at the to-be-attended location, or being a salient physical change in the visual field, but not on those they share with the endogenous cues, such as predictive validity or a $300-\mathrm{msec}$ SOA. Of course, the present results do not imply that attention can never be consciously directed to objects, only that it is not obligatorily object based when directed in response to endogenous spatial cues.

Also, the object-based effect does not rely on the use of a detection task, as these results were found with a discrimination task, nor is it dependent on the target being presented more frequently on the cued object, as in Egly, Driver, and Rafal (1994; Egly, Rafal, et al., 1994). In this experiment, the effect occurred when the target was no more likely to appear on the cued than on the uncued object. In addition to showing that the object-based effect is dependent on exogenous cuing, the data also indicate that the exogenous cue does not have to be a change in the object itself, as in Egly, Driver, and Rafal's work (1994; Egly, Rafal, et al., 1994). The exogenous cues used here were spatially distinct from the object itself. Of course, one could argue that the reported object-based effect did not arise from exogenous cuing, but from the use of cues that easily group with the object, such as the line segments used in this experiment or the brightening of the object's outline used in Egly, Driver, and Rafal (1994). This alternative must await further investigation, as the present data set does not allow its refutation.

The present results are similar to those of Briand and Klein (1987), who demonstrated that when a target's identification requires the integration of features, the effect on response times of exogenous cuing is larger than when identification does not require the integration of features, while the reaction time effects of endogenous cuing are additive with manipulations of whether identification requires feature integration (Briand \& Klein, 1987). Other researchers have shown that feature migrations occur mainly within perceptual groups, and not between groups (e.g., Prinzmetal, 1981), that attention is exogenously drawn to novel perceptual objects (Yantis \& Hillstrom, 1994), and that inhibition of return has an object-based component (Tipper, Driver, \& Weaver, 1991). This general pattern is consistent with exogenous cues affecting the episodic representations of perceptual objects that Kahneman and Treisman (1984; Kahneman, Treisman, \& Gibbs, 1992) have dubbed "object files." Object files maintain the identity of objects by keeping track of an object's location and the perceptual features currently assigned to it. The object-based effect in spatial cuing can be explained if exogenous spatial cues result in a general priming of object files so that the information from that file can be more easily accessed. Exogenous cues would affect the setting up of an object file, the accumulation of information in that file, or the accessing of information from that object file, while endogenous cues would affect earlier and later stages of processing (Klein, 1994).

Normally exogenous cuing has a relatively short time course, with the costs and benefits of exogenous cues being absent, or greatly reduced, by $300 \mathrm{msec}$ (Nakayama \& Mackben, 1989). Egly, Driver, and Rafal's (1994) finding of an object-based effect $300 \mathrm{msec}$ after an exogenous cue seems inconsistent with this typical short time course. However, their finding may simply indicate that the object-based components of spatial cuing are longer lasting than the space-based ones. Kahneman et al. (1992) have reported relatively long-duration, objectspecific priming of letter identities, which shows that long-lasting object-based effects do occur. The inhibition of return following an exogenous cue (Maylor, 1985) demonstrates that exogenous cuing phenomena can have a long duration.

\section{REFERENCES}

Baylis, G. C., \& Driver, J. (1992). Visual parsing and response competition: The effect of grouping factors. Perception \& Psychophysics, 51, 145-162.

Briand, K. A., \& Klein, R. M. (1987). Is Posner's "beam" the same as Treisman's "glue?": On the relation between visual orienting and feature integration. Journal of Experimental Psychology: Human Perception \& Performance, 13, 228-241.

DunCAN, J. (1984). Selective attention and the organization of visual information. Journal of Experimental Psychology: General, 113. 501-517.
EGLY, R, Driver, J. S., \& RAFAL, R. D. (1994). Shifting attention between objects and locations: Evidence from normal and parietal lesion subjects. Journal of Experimental Psychology, 123, 161-177.

Egly, R., Rafal, R., Driver, J., \& Starrveveld, Y. (1994). Covert orienting in the split brain reveals hemispheric specialization for object-based attention. Psychological Science, 5, 380-383.

ERIKSEN, C. W., \& Hoffman, J. E. (1974). Selective attention: Noise suppression or signal enhancement? Bulletin of the Psychonomic Society, 4, 587-589.

Henderson, J. M., \& Macquistan, A. D. (1993). The spatial distribution of attention following an exogenous cue. Perception \& Psychophysics, 53, 221-230.

Kahneman, D., \& Treisman, A. [M.] (1984). Changing views of attention and automaticity. In R. Parasurman \& D. R. Davies (Eds.), Varieties of attention (pp. 29-61). Orlando, FL: Academic Press.

Kahneman, D., Treisman, A. [M.], \& GibBs, B. J. (1992). The reviewing of object files: Object-specific integration of information. Cognitive Psychology, 24, 175-219.

KANWISHER, N., \& DRIVER, J. S. (1992). Objects, attributes, and visual attention: Which, what, and where. Current Directions in Psychological Science, 1, 26-31.

KLEIN, R. (1994). Perceptual-motor expectancies interact with cover visual orienting under conditions of endogenous but not exogenous control. Canadian Journal of Experimental Psychology, 48, 167-181.

KLEIN, R., \& HANSEN, E. (1990). Chronometric analysis of spotlight failure in endogenous visual orienting. Journal of Experimental Psychology: Human Perception \& Performance (pp. 46-65), 16, 790-801.

Ki.ein, R., Kingstone, A., \& Pontefract, A. (1992). Orienting of visual attention. In K. Rayner (Ed.), Eye movements and visual cognition: Scene perception and reading (pp. 46-65). New York: SpringerVerlag.

Kramer, A. F., \& Jacobson, A. (1991). Perceptual organization and focused attention: The role of objects and proximity in visual processing. Perception \& Psychophysics, 50, 267-284.

MAYLOR, E. A. (1985). Facilitatory and inhibitory components of orienting attention in visual space. In M. I. Posner \& O. S. M. Marin (Eds.), Attention and performance XI (pp. 189-204). Hillsdale, NJ: Erlbaum.

Müller, H. J., \& RABbitT, P. M. A. (1989). Reflexive and voluntary orienting of visual attention: Time course of activation and resistance to interruption. Journal of Experimental Psychology: Human Perception \& Performance, 15, 315-330.

Nakayama, K., \& MackbeN, M. (1989). Sustained and transient components of focal visual attention. Vision Research, 29, 1631-1647.

POSNER, M. I. (1980). Orienting of attention. Quarterly Journal of Experimental Psychology, 32, 3-25.

Posner, M. I., Snyder, C. R. R., \& Davidson, B. J. (1980). Attention and the detection of signals. Journal of Experimental Psychology: General, 109, 160-174.

Prinzmetal, W. (1981). Principles of feature integration in visual perception. Perception \& Psychophysics, 30, 330-340.

TIPPER, S. P. (1992). Selection for action: The role of inhibitory mechanisms. Current Directions in Psychological Science, 1, 105-109.

TipPeR, S. P., Driver, J. S., \& Weaver, B. (1991). Object-centered inhibition of return of visual attention. Quarterly Journal of Experimental Psychology, 43A, 289-298.

Yantis, S., \& Hillstrom, A. (1994). Stimulus-driven attentional capture: Evidence from equiluminant visual objects. Journal of Experimental Psychology: Human Perception \& Performance, 20, 95-107.

\section{NOTES}

1. I would like to thank Ray Klein for pointing this out, and suggesting the purely endogenous manipulation.

2 . In other words, each of the six comparisons for each cue type was protected at $p=.0083$, which means that a difference in summed ranks had to exceed 26.59 to be declared significant. The same critical difference was also used in making pairwise comparisons on the accuracy ranks.

(Manuscript received September 14. 1995: revision accepted for publication June 25,1996 .) 